\title{
Effects of repeated lithium injections on temperature, activity, and flavor conditioning in rats
}

\author{
JOHN D. BATSON \\ Furman University, Greenville, South Carolina
}

\begin{abstract}
Two experiments investigated the effects of lithium chloride on activity and rectal temperature in rats. Lithium injections, relative to saline injections in controls, caused decreases in both activity and temperature. Importantly, lithium's effects did not diminish over the course of eight repeated injections, although preexposure to lithium did attenuate its conditioning effectiveness in a flavor-conditioning trial. The results support the idea that drug tolerance is not of great importance in the lithium-mediated US-preexposure effect in flavor conditioning.
\end{abstract}

Lithium chloride $(\mathrm{LiCl})$ has been a very popular drug among researchers interested in flavor-aversion learning. In the flavor-conditioning paradigm, a flavor conditioned stimulus (CS) is paired with a drug unconditioned stimulus (US) to create an aversion to the flavor. Of many drugs tested (see Gamzu, 1977), lithium has proved to be one of the most potent conditioning agents.

Of particular interest in recent studies has been the attenuation of flavor conditioning when the flavor-lithium conditioning trial is preceded by repeated exposure to lithium alone. Some researchers (e.g., Riley, Jacobs, \& LoLordo, 1976) have suggested that this so-called US-preexposure effect might be due to the development of pharmacological tolerance over the course of repeated drug exposures. According to this account, preexposure to lithium reduces its subsequent conditionability because body systems are less responsive to later administrations of the drug.

A second account of the lithium-preexposure effect argues that exposure to the drug per se is less important than associative mechanisms (see Randich \& LoLordo, 1979). According to this "blocking" or associative interference hypothesis, injectionrelated environmental stimuli become associated with lithium toxicosis during preexposure, and these cues then interfere with flavor conditioning through attentional processes. This hypothesis has gained support from experiments that demonstrate the importance of injection-related cues. For example, when flavor conditioning is conducted in an environ-

This research was funded in part by NIMH Grant MH 30788-01 awarded to M. R. Best and M. Domjan. Michael R. Best provided valuable comments on the preparation of this report. Requests for reprints should be addressed to: John D. Batson, Department of Psychology, Furman University, Greenville, South Carolina 29613. mental context that is different from the preexposure context, drug-preexposed animals learn aversions just as readily as nonpreexposed animals (Batson \& Best, 1979; Dacanay \& Riley, 1982). Also, extinction of the injection-related cues prior to the flavor-conditioning trial reinstates the conditioning effectiveness of lithium (Batson \& Best, 1979; Willner, 1978). Results such as these suggest that lithium preexposures can reduce flavor conditioning through associative processes and that pharmacological tolerance does not provide an adequate explanation of the preexposure effect.

Traditionally, these two accounts of the lithiumpreexposure effect-tolerance and associative interference-have been considered to be independent from one another. However, it is conceivable that drug tolerance might actually be mediated by associative processes. Siegel (1978), for example, has shown that the development of tolerance to morphine involves the acquisition of compensatory conditioned responses that are elicited by drug-predictive cues and that counteract the unconditioned responses normally elicited by the drug. Alternatively, Wagner (1982) has suggested that repeated US exposures result in response habituation through specific associative processes. In both cases (compensatory conditioning and habituation to the US), there develops an attenuated response to the US ("tolerance") that is mediated by some associative process(es).

It would seem reasonable, then, to consider whether the lithium-preexposure effect in flavor conditioning might be due to associative processes that act to reduce the overall response to the drug. Surprisingly, in all the literature concerning the lithium-preexposure effect, there is virtually no information about lithium's effects prior to the flavor-conditioning trial. In perhaps the only such investigation, Cain and Baenninger (1977) reported 
that lithium's effects on open-field activity were reduced over three successive administrations of the drug. This result suggests that the lithiumpreexposure effect is indeed due to attenuated responses to the drug. However, some initial pilot studies in my laboratory did not support such a conclusion. Since so little is known about lithium's effects prior to flavor conditioning, experiments were conducted to examine the drug's effects on rectal temperature and activity.

\section{EXPERIMENT 1}

In this experiment, rats were injected with either $\mathrm{LiCl}$ or sodium chloride $(\mathrm{NaCl})$ every other day until a total of eight injections had been given. Rectal temperature was assessed in all subjects before and after each injection to determine if lithium affects this response measure and, more importantly, to discern whether the response to lithium changes as a function of lithium exposure. However, since the experiment was motivated by an interest in the US-preexposure effect in flavor-aversion learning, a flavor-conditioning manipulation was also included. Following the preexposure injections, the subjects in both groups were allowed to consume a saline-flavored solution, and then were injected with lithium. Temperature assessments were made following the conditioning day's lithium injections, and also after a final injection of saline in both groups.

\section{Method}

Subjects. Twelve male albino rats (Holtzman Co., Madison, Wisconsin) served as the subjects. Their weights ranged from 313 to $398 \mathrm{~g}$ on the 1st day of the experiment. They were housed individually in standard $18 \times 18 \times 24 \mathrm{~cm}$ cages in a standard colony rack in a room in which the lights were dimmed between 1800 and $0600 \mathrm{~h}$ daily. The subjects had uninterrupted access to Purina Formulab, and water was made available for 20-30 min daily between 1600 and $1700 \mathrm{~h}$.

Apparatus. Temperature readings were made with a YSI Model 43TF thermometer and a YSI 423 probe (Yellow Springs Instruments Co., Yellow Springs, Ohio). This device yields temperature readings with a $0.05^{\circ} \mathrm{C}$ readability. After the animal had been gently wrapped in a terrycloth towel, a probe was inserted $4 \mathrm{~cm}$ into the rectum and, $40 \mathrm{sec}$ later, the subject's temperature was assessed.

The animals received injections of $\mathrm{LiCl}$ and $\mathrm{NaCl}(.15 \mathrm{M}$, $12 \mathrm{cc} / \mathrm{kg}$, ip).

Procedure. All experimental treatments began between 1000 and $1100 \mathrm{~h}$. On Day 1, each of the subjects was removed from its home cage and was carried a distance of about $4 \mathrm{~m}$ to a small room where its temperature was recorded. Immediately following this initial temperature assessment, each of the subjects was carried back to the home-cage room and was weighed. An injection of either $\mathrm{LiCl}$ (Group $\mathrm{LiCl}, \mathrm{n}=6$ ) or $\mathrm{NaCl}$ (Group $\mathrm{NaCl}$, $\mathrm{n}=6$ ) was administered, and each of the subjects was then returned to its home cage. The subjects remained in the home cages for $.5 \mathrm{~h}$ and then were returned to the small adjacent room for a second temperature assessment. A third temperature reading was made $1 \mathrm{~h}$ later (i.e., $1.5 \mathrm{~h}$ after the injection).

The Day 1 treatments were repeated on Days $3,5,7,9,11$, 13 , and 15. That is, each of the subjects received eight injections of either $\mathrm{LiCl}$ or $\mathrm{NaCl}$, with injections occurring $48 \mathrm{~h}$ apart. Temperatures were recorded immediately before and at .5 and $1.5 \mathrm{~h}$ after each injection. No treatments occurred on Days 2 , $4,6,8,10,12,14$, and 16 .

Beginning on Day 17, Group $\mathrm{LiCl}$ and Group $\mathrm{NaCl}$ received identical treatments. On Day 17, baseline temperatures were recorded immediately before the subjects were weighed, as usual. However, when the subjects were returned to their home cages immediately after being weighed, they received 10-min access to $10 \mathrm{ml}$ of saline solution $(.9 \%, w / v$ in room-temperature tap water), presented in centrifuge drinking tubes. Each of the subjects consumed between 9.0 and $9.5 \mathrm{ml}$ of the saline solution within the 10-min period. 'Then, within $30 \mathrm{sec}$ after the 10 -min drinking period, each of the subjects received a lithium injection, administered in exactly the same way all previous injections had been made. Thus, all subjects received a saline(CS)-lithium(US) conditioning trial on Day 17. Temperature readings were made again 0.5 and $1.5 \mathrm{~h}$ after the injection. No treatments occurred on Days 18-21.

On Day 22 -the saline test day-the subjects in both groups were given access to the saline solution in their home cages for $15 \mathrm{~min}$. Consumption scores for each of the subjects were computed by weighing each drinking tube before and after this 15 min test on an electronic balance accurate to $0.1 \mathrm{~g}$. No treatments were administered on Days 23-26.

On Day 27, the subjects in both groups received a $\mathrm{NaCl}$ injection. Temperature assessments were made immediately before and 0.5 and $1.5 \mathrm{~h}$ after the injection. The Day 27 treatments, then, were exactly like the Day 1 treatments except that the Group $\mathrm{LiCl}$ subjects received a $\mathrm{NaCl}$ injection instead of a $\mathrm{LiCl}$ injection.

\section{Results and Discussion}

The first eight trials. Mean temperatures of the two groups over the first eight injections are displayed in Figure 1. Comparisons of the two groups over

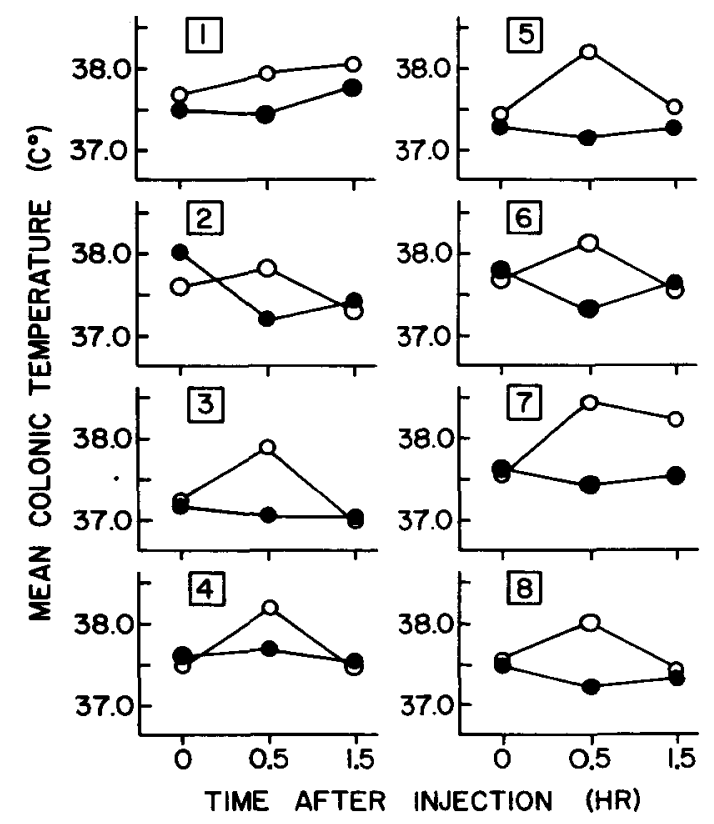

Figure 1. Group mean temperature responses for the two groups of Experiment 1. ISubjects received eight injections of either lithium (filled circles) or saline (open circles), and temperatures were recorded immediately before and 0.5 and $1.5 \mathrm{~h}$ after the injections.] 
the eight trials were made with three analyses of variance (one at each recording interval). Table 1 summarizes the statistical analyses. The two groups differed significantly at the 0.5 -h recording period but not at the 0.0 - (baseline) and 1.5-h intervals. The significant trials effect reflects the day-to-day differences in temperatures within groups and may have been due to various changes in laboratory conditions over days. Importantly, there were no significant interaction effects. The nonsignificant groups $\times$ trials effect at the $0.5-\mathrm{h}$ interval indicates that the differences between the two groups did not change over the course of the eight trials.

Although the group differences at the $0.5-\mathrm{h}$ interval were significant and consistent over the eight trials, we cannot discern from this experiment alone the reasons for the lithium effect. The lithiuminjected subjects showed mean temperature decreases from the 0.0 - to 0.5 -h intervals on seven of the eight trials. Two of these decreases (Trials 2 and 6) were statistically significant (i.e., all six rats showed decreases). This may indicate direct hypothermic effects of lithium. However, the group differences at the 0.5 - $\mathrm{h}$ interval must also be attributed to Group NaCl's temperature increases from the $0.0-$ to $0.5-\mathrm{h}$ intervals. On three occasions (Trials 4,5 , and 7 ), these increases were significant. Increases in temperature following saline injections and temperature assessments are not uncommon (see Siegel, 1978) and may reflect merely the increased "arousal" of nondrugged subjects. Nevertheless, although we may not know all the reasons for the group differences in temperature at the 0.5-h interval, it is clear that this difference was not reduced over the eight lithium injections. These results suggest that the Group $\mathrm{LiCl}$ rats did not develop tolerance to the thermic effects of the drug.

The flavor-conditioning trial. On Day 17 of the experiment, both groups were treated identically for the first time. Both groups received a lithium injection after 10-min access to saline-flavored water. Temperature recordings were made as usual before and twice after the injection. The mean temperature responses of the two groups are presented in the top half of Figure 2. This figure shows that lithium produced similar responses in the two groups, despite the fact that Group $\mathrm{LiCl}$ had experienced lith-

Table 1

F Test Results for the First Eight Trials of Experiment 1

\begin{tabular}{lccccc}
\hline & & \multicolumn{3}{c}{ Recording Interval (Hours) } \\
\cline { 4 - 6 } Effect Tested & df & .0 & .5 & 1.5 \\
\hline Groups (LiCl vs. NaCl) & 1,10 & .01 & $15.54^{* *}$ & .27 \\
Trials (8 injections) & 7,70 & $2.76^{*}$ & $2.41^{*}$ & $4.18^{* *}$ \\
Groups $\times$ Trials & 7,70 & .54 & 1.03 & .56 \\
\hline Note- $n=6$ per group. & $* p<.05$. & $* * p<.01$.
\end{tabular}

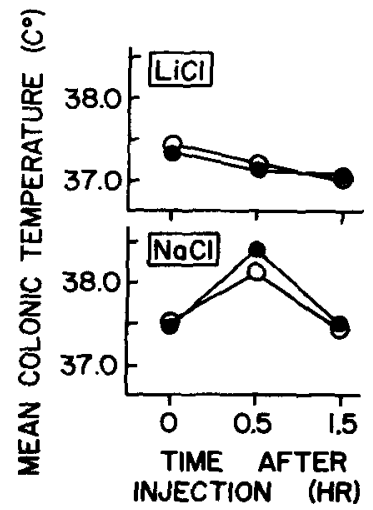

Plgare 2. Group mean temperature responses for the two groups of Experiment 1 following the elght initial injections. (The top groph deplets reaponses of both groups to lithium, and the bottow graph deplets responses of both groups to saline. Filled circles represent hithium-pretreated rats, and open circles represent saline-pretreated rats.)

ium on eight previous occasions. Three $t$ tests (one at each interval) revealed nonsignificant differences between the two groups [largest $t(10)=.34$ ]. Thus, eight preexposures to lithium caused no significant change in its effectiveness on the ninth trial. If tolerance had developed, we would have expected differences between the two groups on Day 17.

Since both groups reacted similarly to lithium on Day 17, one might predict that lithium would be equally effective in conditioning flavor aversions in both groups on this day. However, when both groups were tested for their willingness to consume the saline-flavored CS on Day 22, it was clear that the groups had acquired aversions of different magnitudes. Group $\mathrm{LiCl}$ drank a mean of $13.4 \mathrm{~g}$ of the saline $\mathrm{CS}$ during the 15-min test, and Group $\mathrm{NaCl}$ consumed a mean of $3.6 \mathrm{~g}$. This dramatic difference in saline consumption indicates that only Group $\mathrm{NaCl}$ formed a strong aversion during the salinelithium conditioning trial on Day 17 , and that the eight lithium preexposures acted to reduce the conditioning effectiveness of the drug in Group $\mathrm{LiCl}$. This result replicates the "US-preexposure effect" reported by many others (e.g., Holman, 1976). Unlike previous reports of the phenomenon, however, Experiment 1 provides information about one of lithium's "unconditioned" effects during the conditioning and preexposure phases of the procedure.

The final, saline-injection trial. On Day 27, the subjects in both groups were treated identically again. A saline injection was administered, and temperatures were recorded as usual. The groups' mean responses on this trial are plotted in the lower half of Figure 2. There were no significant differences between the groups at any of the three recording intervals [largest $t(10)=.91]$. Thus, this 
saline injection affected the two groups similarly, despite the two groups' different histories.

\section{EXPERIMENT 2}

The initial experiment in this report demonstrated that eight lithium injections caused a dramatic disruption in the drug's ability to condition a flavor aversion even though the drug preexposures produced no observable diminution in lithium's thermic effects. Experiment 2 was conducted to examine lithium's effects on another response-activity. Cain and Baenninger (1977) reported that openfield activity of rats was decreased by lithium and that this hypoactivity was diminished over three successive administrations of the drug. Such "habituation" or tolerance to lithium was not observed for temperature responses in Experiment 1. Furthermore, recent associative accounts of the lithiumpreexposure effect seem to suggest that body systems-at least those responsible for flavor conditioning-do not habituate to the drug. Since so little was known about lithium's effect on activity, Experiment 2 was conducted to examine whether lithium-induced changes in this response might be reduced after several lithium exposures. Rats were injected with either $\mathrm{LiCl}$ or $\mathrm{NaCl}$ every other day until eight injections had been given, and their activity was recorded after each injection. Since the effects of lithium preexposure on flavor conditioning have been well documented, a flavor-conditioning manipulation was not included in Experiment 2.

\section{Method}

Subjects. Sixteen experimentally naive adult male rats (Holtzman Co., Madison, Wisconsin) were assigned randomly to one of two groups. Both groups contained eight subjects, and the mean weights of the groups on Day 1 of the experiment were 236.1 and $243.8 \mathrm{~g}$, respectively. Purina Formulab or Wayne Lab Blox food was always present in the home cages. Access to water was restricted to $20 \mathrm{~min}$ each day, as in Experiment 1 and most other studies of the lithium-preexposure effect. This daily watering session occurred between 1030 and $1130 \mathrm{~h}$. The lights were dimmed between 1900 and $0600 \mathrm{~h}$. The subjects lived in individual cages, as in Experiment 1.

Apparatus. Two Columbus Instruments (Columbus, Ohio) Automex activity monitors were used to measure activity. These monitors generate radio-frequency beams from below a Plexiglas platform. The rats were placed on top of the platform and were covered with an inverted stainless steel cage [18 (height) $\times 40$ (width) $\times 24$ (depth) $\mathrm{cm}$ ] that was grounded to the chassis of the monitor to confine all generated beams within the cage. As the emitted radio-frequency beams were broken by the rats' movements, digital signals were generated. These signals were counted by relay and recording equipment located in an adjacent room.

Procedure. On Day 1 of the experiment, the subjects in Group $\mathrm{LiCl}$ received an injection of $\mathrm{LiCl}$, and those in Group $\mathrm{NaCl}$ received an injection of $\mathrm{NaCl}$ (both $.15 \mathrm{M}, 12 \mathrm{cc} / \mathrm{kg}$, ip). The injections occurred between 0730 and $0930 \mathrm{~h}$, immediately after the subjects had been weighed. Each of the subjects was placed on an activity monitor within $1 \mathrm{~min}$ after the injection, and cumulative activity scores were recorded every $5 \mathrm{~min}$ for a total of $20 \mathrm{~min}$.

The Day 1 procedures were repeated every $48 \mathrm{~h}$, until the subjects had received a total of eight injections of either lithium or saline. That is, injections and activity recordings occurred on odd-numbered days of the experiment through Day 15. No treatments occurred on even-numbered days.

Each of the rats always experienced the same activity monitor, and half the rats in each group were tested on each monitor.

\section{Results and Discussion}

Unlike in Experiment 1, in which the results for the groups were different only at a certain time following each injection, the activity responses of the two groups here were not affected differentially within the 20-min recording sessions. Therefore, the differences between the groups were analyzed by comparing total activity scores at the end of each 20-min test. These data are presented in Figure 3. The Group $\mathrm{LiCl}$ subjects were less active than the Group $\mathrm{NaCl}$ rats on each of the eight trials. Whereas Group NaCl's activity level remained relatively consistent after the initial two trials, Group LiCl's responding remained depressed, although there was more variability from trial to trial in the lithium-treated subjects than in the saline-treated animals. Also, each group displayed habituation to the activity monitors: More activity occurred during the initial test than during any of the next seven trials. An analysis of variance confirmed these effects. The effect of groups ( $\mathrm{LiCl}$ vs. $\mathrm{NaCl}$ ) was significant $[F(1,10)=22.45, p<.01]$, as was the effect of the eight repeated tests $[F(7,98)=5.29$, $\mathrm{p}<.01]$. Importantly, the groups $\times$ tests interaction was not significant $[F(7,98)=.34]$. The absence of an interaction here suggests that the differences between the groups were relatively constant over each of the eight trials.

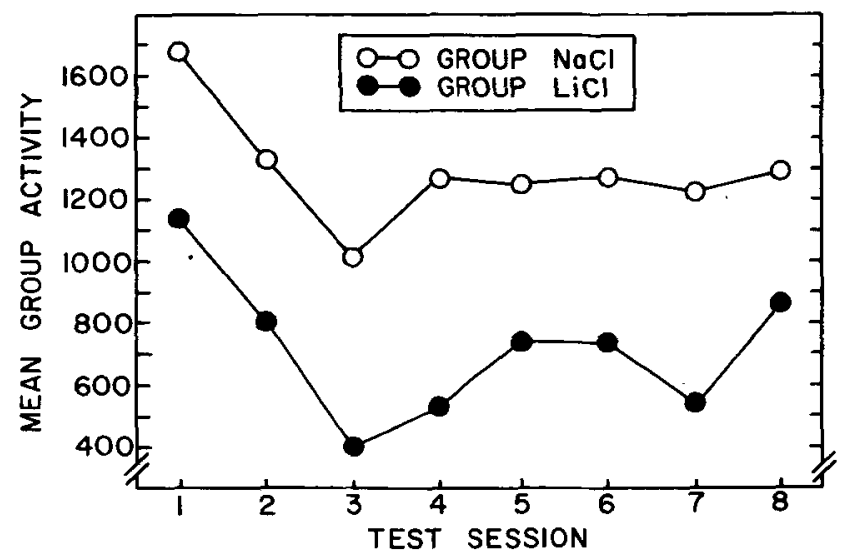

Figure 3. Group mean activity responses for the two groups of Experiment 2. (Subjects received eight injections of either lithium or saline, and activity was recorded for 20 min following each injection.) 
The relatively consistent hypoactive response caused by each of the eight lithium injections is a significant result, since Cain and Baenninger (1977) observed diminished lithium-induced hypoactivity in successive lithium administrations. Although the results of Experiment 2 clearly conflict with those of Cain and Baenninger, the reasons for this discrepancy are not clear. There are a number of methodological differences between the two studies. These include: sex, weight, and, possibly, strain of subjects; access to water (available for $20 \mathrm{~min}$ or $24 \mathrm{~h}$ a day); method of lithium administration (ip injection vs. intubation); dose of lithium; method of recording activity (electronic monitoring vs. manual open-field observation); length of recording interval (20 vs. $30 \mathrm{~min}$ ); and number of lithium administrations. Cain and Baenninger also familiarized subjects with the testing chamber to record baseline activity measures, whereas there was no such familiarization in the present study. Although such differences in procedures may be responsible for the different outcomes, an adequate account of the differing results will require additional testing.

\section{GENERAL DISCUSSION}

The two experiments reported here examined the effects of lithium on temperature and activity in rats. Relative to saline-injected controls, lithiuminjected rats demonstrated attenuated responses following each administration of the drug. Moreover, lithium's effects showed no significant change from early in the series of injections to late in the series. These results indicate that temperature and activity responses do not habituate or become tolerant to lithium and are consistent with other reports that have not observed lithium tolerance (see Johnson, 1979).

Whereas lithium exposures maintained relatively consistent effects on activity and temperature responses, the same lithium preexposures greatly disrupted lithium-mediated flavor conditioning. These differential effects provide additional support for the associative interference (or blocking) account of the so-called US-preexposure effect. This hypothesis suggests that injection-related environmental cues become associated with lithium toxicosis during preexposure and then interfere with flavor conditioning through attentional processes. Several other experiments with lithium support such an associative interpretation of the preexposure effect caused by this drug. For example, flavor conditioning is not affected by lithium preexposure when the preconditioned environmental cues are extinguished (Batson \& Best, 1979) or when they are unreliably paired with the lithium preexposures
(Willner, 1978). Thus, it is generally agreed that associative processes are more important than drug tolerance in the lithium version of the US-preexposure effect. One important outcome of the present experiments is that the associative processes responsible for the blocking of flavor conditioning do not operate by reducing the overall effectiveness of the drug.

A recent report by Dacanay and Riley (1982), however, demonstrates that associative interference and tolerance may be drug specific and that each of these processes may attenuate flavor conditioning. These researchers compared the drug-preexposure effects caused by lithium and morphine. Their results showed that, whereas the lithium effect depends upon associations of the drug effect with injection-related stimuli, the morphine effect appears to depend upon pharmacological processes. Thus, tolerance may remain a valid account of some drug-preexposure effects, even though it is clear that associative processes are more important with lithium. The two experiments reported here provide additional support for the associative account of the lithium preexposure effect by showing that tolerance for lithium does not develop in temperature and activity response systems. These results are of further importance because most of the literature concerning lithium preexposure effects in flavor conditioning has not examined lithium's effects during the preexposure phase of the paradigm.

\section{REFERENCES}

Batson, J. D., \& Best, P. J. Drug-preexposure effects in flavor-aversion learning: Associative interference by conditioned environmental stimuli. Journal of Experimental Psychology: Animal Behavior Processes, 1979, 5, 272-283.

Cain, N. W., \& Baenninger, R. Habituation to illness: Effects of prior experience with the US on the formation of learned taste aversions in rats. Animal Learning \& Behavior, 1977, 5, 359-364.

Dacanay, R. J., \& Riley, A. L. The UCS preexposure effect in taste aversion learning: Tolerance and blocking are drug specific. Animal Learning \& Behavior, 1982, 10, 91-96.

GAMzU, E. The multifaceted nature of the post ingestional consequence-Is there a single common factor? In $L$. $M$. Barker, M. R. Best, \& M. Domjan (Eds.), Learning mechanisms in food selection. Waco, Tex: Baylor University Press, 1977.

Holman, E. W. The effect of drug habituation before and after taste aversion learning in rats. Animal Learning \& Behavior, 1976, 4, 329-332.

Johnson, F. N. The psychopharmacology of lithium. Neuroscience \& Biobehavioral Reviews, 1979, 3, 15-30.

RANDich, A., \& LoLordo, V. M. Associative and nonassociative theories of the UCS preexposure phenomenon: Implications for Pavlovian conditioning. Psychological Bulletin, 1979, 86, 523-548.

RILEY, A. L., Jacobs, W. J., \& LoLoRdo, V. M. Drug exposure and the acquisition and retention of a conditioned taste aversion. Journal of Comparative and Physiological Psychology, 1976, 90, 799-807.

Siegel, S. Tolerance to the hyperthermic effect of morphine 
in the rat is a learned response. Journal of Comparative and Physiological Psychology, 1978, 92, 1137-1149.

WAgNER, A. R. SOP: A model of automatic memory processing in animal behavior. In N. S. Spear \& R. Miller (Eds.), Information processing in animals: Memory mechanisms. Hillsdale, N.J: Erlbaum, 1982.

WillNer, J. A. Blocking of a taste aversion by prior pairings of exteroceptive stimuli with illness. Learning and Motivation, $1978,9,125-140$.

\section{NOTE}

1. The drinking tubes were filled with $10 \mathrm{ml}$ of the saline solution, but the 10-ml limit was never achieved because some fluid invariably was trapped inside the tube around the metal spout.

(Manuscript received June 8, 1982;

revision accepted for publication January $26,1983$. ) 